\title{
APLICAÇÃO DO MODELO ANALÍTICO DA CADEIA DE VALOR NA ANÁLISE DA ESTRATIFICAÇÃO COMPETITIVA EM UM APL
}

\section{APPLICATION OF THE VALUE CHAIN MODEL FOR ANALYSIS OF THE EVOLUTIONARY COMPETITIVE STRATIFICATION IN AN INDUSTRIAL CLUSTER}

\author{
Andréia Aparecida Albino*andreia.albino@ufv.br \\ Sebastião Décio Coimbra de Souza** decio@uenf.br \\ Afonso Augusto Teixeira de Freitas de Carvalho Lima** afonsoli@ufv.br.; \\ Marcos Inácio Severo de Almeida ****misevero@yahoo.com.br \\ Ricardo Roberto Behr ${ }^{* * * *}$ ricardobehr@hotmail.com \\ * Faculdade Presidente Antônio Carlos de Ponte Nova \\ ** Universidade Estadual Norte Fluminense \\ *** Universidade Federal de Viçosa \\ **** Universidade Federal de Goiás (UFG) \\ ***** Universidade Federal do Espírito Santo
}

\begin{abstract}
Resumo: Aplicou-se o modelo de Cadeia de Valor ao estudo do desempenho relativo entre empresas em um APL moveleiro como meio para se estratificar padrões competitivos evolucionários das firmas em três grupos: forging ahead, catching up e falling behind. O levantamento de dados foi realizado através de um estudo de caso de natureza descritiva com abordagem qualitativa e quantitativa em uma amostra de 16 firmas do aglomerado. O método de estratificação de padrões competitivos por meio da Cadeia de Valor permitiu verificar a diversidade existente entre as firmas do aglomerado em vários pontos e, como tal, serve como uma medida de desempenho relativo entre as firmas em termos competitivos. Os resultados permitem concluir que produto, processo produtivo, mercado e gestão são elementos que diferenciam os grupos de padrões identificados no APL. Sugere-se a adoção do método de estratificação competitiva ao estudo da competitividade em outros aglomerados industriais com a aplicação do modelo de Cadeia de Valor, que se mostra promissor para identificação das especificidades e diferenciação dos fatores de vantagens competitivas das empresas, e que pode indicar aspectos que merecem atenção para futuras melhorias, bem como direcionar ações mais equilibradas do Poder Público para o fomento da competitividade e sustentabilidade em APLs.
\end{abstract}

Palavras chave: Arranjo Produtivo Local. APL Moveleiro de Ubá. Abordagem Evolucionária. Estratificação de Padrões Competitivos. Cadeia de Valor.

Abstract: We applied the Value Chain model to study the relative performance among firms in a furniture cluster as a means of stratifying competitive evolutionary patterns of firms into three groups: forging ahead, catching up and falling behind. The survey data was conducted through a descriptive case study with qualitative and quantitative approach in a sample of 16 firms. The method of stratification by competitive patterns through the value chain analysis showed the diversity among firms in the cluster by several points and, as such, serves as a measure of relative performance among firms in competitive terms. The results indicate that product, production process, market and management are elements that differentiate the groups of patterns identified in the firms. We suggest the adoption of the method of competitive stratification to the study of competitiveness in other industrial clusters through Value Chain model, which shows promise for the specific identification and differentiation of factors for competitive advantage of firms, and that may indicate aspects that deserve 
attention for future improvements, as well as direct actions more balanced the governance to promote competitiveness and sustainability of the cluster.

Keywords: Industrial cluster. Furniture cluster. Evolutionary approach. Competitive stratification. Value chain model.

\section{INTRODUÇÃO}

Para as micro, pequenas e médias empresas (MPME), a configuração em rede representa uma opção estratégica para a competitividade, pois, na maioria das vezes, elas apresentam dificuldades, tais como: obter melhores preços e vantagens na compra de matérias-primas e componentes, altos custos de participação em feiras, bem como em campanhas publicitárias, reciclagem e treinamento da mão de obra, aluguel. Se esses problemas dificilmente desaparecerão, podem, contudo, ter seus efeitos neutralizados ou amenizados pela ação coletiva em aglomerações produtivas ou Arranjos Produtivos Locais (APLs), fato que ressalta a sua importância para o desenvolvimento local e regional de tais aglomerações (BALESTRIN; VARGAS, 2004).

É reconhecido que o aproveitamento das sinergias coletivas geradas pela participação em APLs efetivamente fortalece as chances de sobrevivência e crescimento das empresas (LASTRES; CASSIOLATO; MACIEL, 2003). A lógica do apoio aos APL's parte do pressuposto que diferentes atores locais podem mobilizarse e, de forma coordenada, identificar suas demandas coletivas, por iniciativa própria ou por indução de entidades, públicas ou não, envolvidas com o segmento (CARRIE, 1999).

As empresas em um APL, normalmente, apresentam variações de padrões, por exemplo, em termos de tamanho, estágio de desenvolvimento, nível tecnológico, categorias e linhas de produtos, modelos de gestão, entre outros fatores diferenciadores (LASTRES; CASSIOLATO; MACIEL, 2003). Nesse contexto, o APL moveleiro de Ubá demonstra importância no cenário nacional, com sua inclusão entre os onze APLs selecionados para receber apoio integrado do Governo Federal para execução das ações necessárias ao crescimento de toda a região (INTERSIND, 2008), de modo que estudos que o apresentam como objetos de estudo têm-se tornado frequentes. Entretanto, tem-se verificado que tais estudos 
são geralmente descritivos no que se refere às origens de sua formação e suas características econômicas atuais, não se tendo encontrado análises conceituais adaptadas às questões locais, que levem em consideração a dinâmica e mecanismos da competitividade que podem ser percebidos internamente no APL (SOUZA, 2003; SOUZA \& ARICA , 2006; ALBINO, 2009).

Abordagens como o modelo do Diamante de Porter' e dos "Arranjos e Sistemas Produtivos Locais" "ii têm sido utilizadas no estudo dos APL's, porém, estas não captam as diversidades internas dos polos, em termos de padrões de comportamento, graus de desenvolvimento e posição relativa das empresas no APL (ALBINO et al. 2009; GALDÁMEZ, et al., 2009). Nesse contexto, Albino et al. (2010) evidenciaram a possibilidade de aplicação da estrutura analítica baseada no modelo da Cadeia de Valor proposto por Porter (1989), como forma de identificar diferentes padrões competitivos em aglomerações industriais. O objetivo deste trabalho é apresentar a aplicação de tal estrutura para o caso do APL moveleiro de Ubá, o que pode contribuir para identificação de pontos que merecem mais cuidado por parte das empresas e que se mostram importantes para sua sobrevivência e desenvolvimento. Além disso, trabalhos dessa natureza têm sua importância ressaltada por fornecer subsídios para a definição do tratamento que deve ser dispensado a cada grupo por parte do Poder Público.

Este artigo apresenta, além da presente seção: i) referencial teórico acerca do modelo da Cadeia de Valor e da estratificação competitiva para o aglomerado em questão; ii) procedimentos metodológicos; iii) resultados e discussões; iv) principais conclusões, além das referências bibliográficas.

\section{REFERENCIAL TEÓRICO}

De acordo com a abordagem dinâmica da competitividade, fatores como o capital humano, fatores técnicos como capacidade de adaptação a novas tecnologias, habilidade gerencial para manter e expandir relacionamentos internos e externos à firma com firmas correlatas, fornecedores, clientes, órgãos públicos, instituições de pesquisa, entre outros influenciam a habilidade de a firma obter e manter uma posição lucrativa face às mudanças tecnológicas, econômicas e sociais, 
bem como a outros desafios do ambiente (FERRAZ, et al., 1997; SOUZA, 2003; ZENONE, 2007). De acordo com Porter (1989), a cadeia de valor é um instrumento básico para diagnosticar a vantagem competitiva e descobrir maneiras de criá-la e sustentá-la. O autor se baseia em modelo genérico para dividir as atividades da empresa em atividades primárias (logística interna, operações, logística externa, marketing e vendas e serviços) e de suporte (Infraestrutura da firma, Gestão de Recursos Humanos, Desenvolvimento da Tecnologia e Compras e Suprimentos).

Segundo Porter (1989), toda empresa é uma reunião de atividades para projetar, produzir, comercializar, entregar e sustentar seu produto. A essa reunião de atividades dá-se o nome de cadeia de valor. Em termos competitivos, a "[...] a cadeia de valor [...] é o conjunto interligado de todas as atividades, [...] desde uma fonte básica de matérias-primas [...] até a entrega do produto final [...]" (SHANK e GOVINDARAJAN, 1993, p. 13).

Porter e Millar (1999) consideram dois tipos de atividades que compõem a cadeia de valor: atividades primárias, envolvidas com a transformação direta dos produtos físicos; e atividades de apoio ou suporte, que são as que só atuam sobre os produtos de maneira indireta, pois apenas afetam as atividades primárias na tentativa de torná-las mais produtivas.

O Quadro 1 resume as atividades primárias e de apoio, segundo Porter (1992).

\begin{tabular}{|l|lr|}
\hline \multicolumn{1}{|c|}{ Atividades Primárias } & \multicolumn{3}{|c|}{ Atividades de Apoio } \\
\hline $\begin{array}{l}\text { Logística interna: recebimento, } \\
\text { estocagem e distribuição de } \\
\text { insumos e produtos. }\end{array}$ & $\begin{array}{l}\text { Infraestrutura da empresa: inclui atividades como } \\
\text { gerência geral, planejamento, finanças, contabilidade, } \\
\text { problemas jurídicos, questões governamentais e gerência } \\
\text { de qualidade. }\end{array}$ \\
\hline $\begin{array}{l}\text { Operações: processo produtivo e } \\
\text { transformação dos insumos em } \\
\text { bens. }\end{array}$ & $\begin{array}{l}\text { Desenvolvimento de tecnologia: esforços para } \\
\text { aperfeiçoar o produto e o processo. }\end{array}$ & \multicolumn{1}{l|}{} \\
\hline $\begin{array}{l}\text { Logística externa: coleta, } \\
\text { estocagem e distribuição dos bens } \\
\text { finais aos compradores. }\end{array}$ & $\begin{array}{l}\text { Gerência de Recursos Humanos: contratação, } \\
\text { treinamento, desenvolvimento, remuneração, } \\
\text { planejamento de cargos, entre outros elementos, } \\
\text { direcionados aos colaboradores e à melhoria do seu } \\
\text { desempenho. }\end{array}$ \\
\hline $\begin{array}{l}\text { Marketing e Vendas: provisão de } \\
\text { um mercado para os bens } \\
\text { produzidos }\end{array}$ & $\begin{array}{l}\text { Aquisição: compra de insumos empregados na Cadeia } \\
\text { de Valor. }\end{array}$ \\
\hline $\begin{array}{l}\text { Assistência técnica: atendimento } \\
\text { ao cliente após aquisição do } \\
\text { produto. }\end{array}$ & & \\
\hline
\end{tabular}

Quadro 1 - Atividades primárias e de apoio.

Fonte: Porter (1992). 
Uma série de trabalhos ${ }^{i i i}$ utilizou o modelo da cadeia de valor para analisar setores. Outros procuraram identificar a cadeia de valor de setores específicos. $O$ que há de comum nos estudos é o consenso de que o modelo da cadeia de valor representa uma estrutura analítica utilizável ao desenvolvimento de trabalhos com diversos objetivos relacionados com o entendimento da competitividade nos setores. Nader e Sachs (2008), por exemplo, buscaram identificar de que maneira os Sistemas Integrados de Gestão Empresarial gerenciam as áreas funcionais da indústria mineral e se eles se compatibilizam com os requisitos de Tecnologia da Informação da cadeia de valor mineral. Crain e Abraham (2008), por sua vez, apresentam uma abordagem que pressupõe o processo de análise dos clientes a partir do conceito de cadeia de valor, comentando que esse é um processo relativamente novo. Os autores propõem identificar necessidades de clientes estratégicos a partir da cadeia de valor.

Conforme apresentado em Albino (2009), a adoção do modelo da Cadeia de Valor como estrutura analítica para identificação dos fatores competitivos permite verificar a diversidade existente entre empresas em um mesmo aglomerado e, por conseqüência, a estratificação de padrões das empresas em grupos distintos. Além disso, essa abordagem se constitui em uma forma de análise do desempenho relativo entre as empresas, contribuindo para o entendimento do processo competitivo interno do aglomerado.

\subsection{Estratificação competitiva}

A premissa da estratificação tem como base a teoria econômica evolucionária, que pressupõe comportamentos e ações individuais e eventos locais de adaptação ao ambiente como fonte crítica da diversidade e mudança (DOSI, 1988, 1995; NELSON; WINTER, 1982).

Baseado em princípios evolucionários, Souza (2003) propôs uma metodologia para se estudar a dinâmica competitiva em APLs, a partir da estratificação das firmas em três grupos distintos: i) Grupo 1 (forging ahead) - as que "pulam na frente", aquelas firmas que adotam estratégias de mudança tecnológica e tomam decisões de investimento, assumindo, assim, maiores riscos, definindo uma trajetória 
competitiva; ii) Grupo 2 (catching-up) - empresas que buscam seguir as líderes, porém, apresentando certa defasagem tecnológica e organizacional, trabalhando mais com imitações; e; iii) Grupo 3 (falling back) - aquelas empresas que "ficam para trás" na dinâmica competitiva local, caracterizadas por não conseguir acompanhar avanços tecnológicos e exigências diversas do mercado, com tendência de perda de mercado ou ao desaparecimento.

Para Souza e Arica (2006), a interação entre elementos internos e externos à empresa contribui para o processo de estratificação, como a tecnologia empregada no processo produtivo, os métodos e rotinas adotados, os tipos de produto e serviços, as estratégias de mercado, entre outros, que geram a estratificação em grupos dentro de um determinado arranjo. A estratificação competitiva evolucionária pode ser definida como o processo de classificação ou separação das empresas em grupos com base em padrões e critérios da dinâmica competitiva e em princípios da teoria econômica evolucionária. Trabalhos dessa natureza têm sua importância ressaltada por fornecer subsídios para a definição do tratamento que deve ser dispensado a cada grupo (SOUZA; ELER; ARICA, 2003; SOUZA; ARICA, 2006; ALBINO et al. 2009; ALBINO, 2009).

De acordo com Souza (2003, p. 19), “a estratificação das empresas pode ser vista como um fenômeno decorrente da dinâmica competitiva do sistema e da capacidade de adaptação de cada componente frente a um ambiente em constante processo de mudança". Em nível microdinâmico, essa estratificação é verificada por meio da dotação de recursos e dos índices de desempenho de cada empresa, que afetam suas estratégias de mercado. Souza e Arica (2006) propõem uma abordagem evolucionária estratificada por constituir uma alternativa potencialmente promissora para o estudo da dinâmica competitiva em APLs, permitindo uma análise segmentada do ambiente competitivo e a identificação de padrões característicos de cada agrupamento. Entender a formação de segmentações e a dinâmica competitiva nesses sistemas é uma condição fundamental para a proposição de planos e programas compatíveis com a realidade local, de modo a superar deficiências técnicas, contornar barreiras comerciais, direcionar novos investimentos e preservar condições socioambientais satisfatórias (ALBINO, 2009). 


\subsection{Apresentação do Objeto de Estudo - O APL moveleiro de Ubá}

No início do século $X X$, a entrada dos imigrantes italianos resultou em mão de obra para trabalhar nas lavouras de café e fumo. Esta mão de obra apresentava forte vocação para manufatura e trabalho artístico. A partir da perda de significância da cultura do fumo (1960), uma alternativa foi o investimento no setor moveleiro (INTERSIND, 2004). A produção moveleira iniciou com algumas fábricas e atualmente, conta com cerca de 400 empresas instaladas em 8 municípios que integram o polo: Ubá, Visconde do Rio Branco, São Geraldo, Tocantins, Piraúba, Rio Pomba, Rodeiro e Guidoval.

A Figura 1 apresenta o desenvolvimento da indústria moveleira de Ubá.

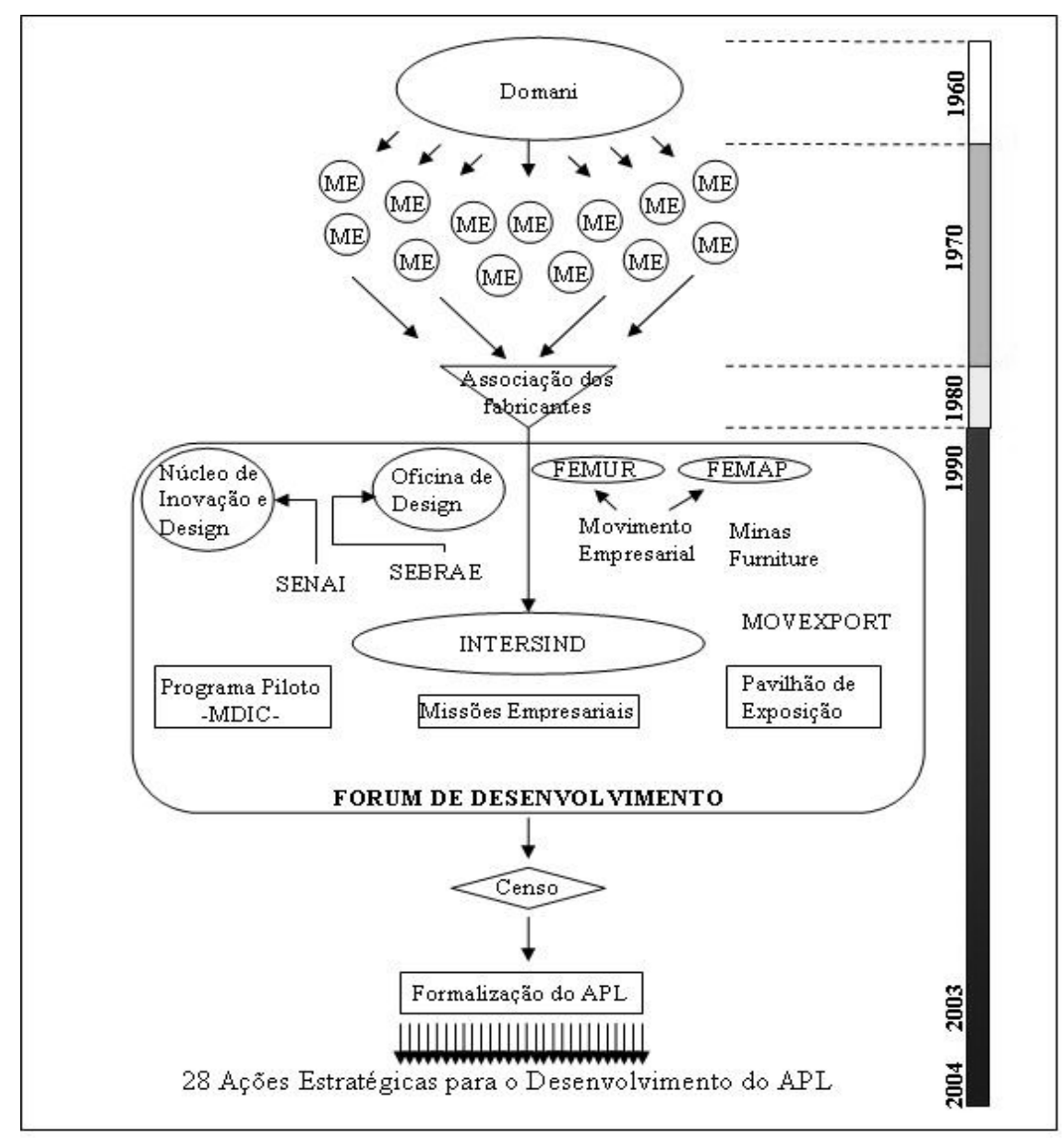

Figura 1 - Desenvolvimento da Indústria Moveleira de Ubá.

Fonte: Adaptado de Silva (2008). 


\section{PROCEDIMENTOS METODOLÓGICOS}

Neste trabalho, a metodologia proposta por Souza (2003) fundamentou a premissa da estratificação competitiva para o caso do APL moveleiro de Ubá e a estrutura da Cadeia de Valor foi utilizada como forma de demonstrar a possibilidade de estratificar as empresas do referido APL em grupos com padrões competitivos diferenciados. A aplicação foi realizada através de um estudo de caso, de natureza descritiva e abordagem qualitativa e quantitativa. Para Bruyne et al. (1991), o estudo de caso é uma forma rica de pesquisa, uma vez que reúne informações tão numerosas e detalhadas quanto possível, procurando apreender a totalidade da situação. Tal estudo foi realizado em duas etapas:

Na primeira etapa, foram entrevistados 12 agentes estratégicos do APL que indicaram possíveis empresas a serem visitadas, tendo por base a premissa da estratificação em três grupos. Os agentes estratégicos entrevistados foram escolhidos por ocuparem cargos que propiciam maior conhecimento sobre a dinâmica do APL. Os agentes entrevistados foram os seguintes:

- Secretário Municipal de Desenvolvimento na gestão 2005-2008;

- Analista do Banco Nacional do Desenvolvimento (BNDES), unidade local;

- Gestor Regional do Serviço de Brasileiro de Apoio às Micro e Pequenas Empresas;

- Gestor da Agência de Desenvolvimento de Ubá e Região (Adubar);

- Sindicato Intermunicipal das Indústrias de Marcenaria de Ubá (Intersind), sendo que nesse órgão, foram realizadas duas entrevistas, uma com a gerência administrativa e outra com a coordenação do APL;

- Coordenador das ações para o APL de Ubá do Instituto Euvaldo Lodi;

- Presidente do Movimento Empresarial;

- Vice-presidente da Federação das Indústrias de Estado de Minas Gerais e empresário do setor;

- Empresário da indústria moveleira e fornecedor de matéria-prima para o polo;

- Empresário da área de Tecnologia de Informação (TI) que atende às empresas do APL; e 
- Diretor de um grupo de cinco empresas do APL.

Na segunda etapa, procedeu a coleta de dados. Nesta etapa foram visitadas 16 empresas do APL moveleiro de Ubá, nas quais foram aplicados formulários com perguntas abertas e fechadas referentes às atividades da Cadeia de Valor, conforme apresentadas no Quadro 2. A identificação dos grupos de padrões se deu a partir de notas atribuídas pelos respondentes para cada quesito investigado. Ao final da coleta dos dados, utilizou-se da análise de freqüência das respostas obtidas durante a aplicação dos formulários.

\begin{tabular}{|c|c|c|}
\hline $\begin{array}{c}\text { Atividades de } \\
\text { Apoio }\end{array}$ & Fatores Considerados & Elementos verificados \\
\hline \multirow{3}{*}{ Infraestrutura } & $\begin{array}{l}\text { Sistemas de Gestão; } \\
\text { Questões legais }\end{array}$ & $\begin{array}{l}\text { Informatização das operações de } \\
\text { gestão, } \\
\text { RSE. }\end{array}$ \\
\hline & Organização financeira & $\begin{array}{l}\text { Gestão Financeira } \\
\text { Financiamento } \\
\text { Formulação de Preços }\end{array}$ \\
\hline & $\begin{array}{lll}\text { Atividades } & \text { previstas } & \text { no } \\
\text { Planejamento } & & \\
\end{array}$ & $\begin{array}{l}\text { Processo Comunicativo } \\
\text { Metas e planos formalizados }\end{array}$ \\
\hline \multirow{6}{*}{$\begin{array}{l}\text { Gerenciamento } \\
\text { de Recursos } \\
\text { Humanos }\end{array}$} & Contratação & $\begin{array}{lll}\begin{array}{l}\text { Métodos } \\
\text { contratação. }\end{array} & \text { empregados } & \text { para } \\
\end{array}$ \\
\hline & Remuneração & $\begin{array}{l}\text { Plano de cargos e salários, } \\
\text { pagamento de horas extras, } \\
\text { recompensas por serviços bem } \\
\text { prestados e para quem não falta ao } \\
\text { trabalho. }\end{array}$ \\
\hline & Desenvolvimento de Pessoas & $\begin{array}{l}\text { Incentivo para que as pessoas } \\
\text { continuem a estudar. }\end{array}$ \\
\hline & Segurança do trabalho & Uso de EPIs. \\
\hline & Plano de Benefícios & O que contém o plano \\
\hline & Qualificação da mão de obra & \\
\hline $\begin{array}{c}\text { Desenvolvimento } \\
\text { de tecnologia }\end{array}$ & P \& D e inovação & $\begin{array}{l}\text { Parcerias; Desenvolvimento } \\
\text { novos produtos e processos. }\end{array}$ \\
\hline Aquisição & $\begin{array}{l}\text { Formação de setor de compras; } \\
\text { Estreitamento das relações com } \\
\text { fornecedores. }\end{array}$ & $\begin{array}{l}\text { Existência de pessoas qualificadas } \\
\text { para comprar. }\end{array}$ \\
\hline \multicolumn{3}{|l|}{$\begin{array}{l}\text { Atividades } \\
\text { Primárias }\end{array}$} \\
\hline Logística interna & $\begin{array}{l}\text { Recebimento de insumos } \\
\text { Estocagem } \\
\text { Distribuição de insumos e produtos }\end{array}$ & $\begin{array}{l}\text { Existência de setor de recebimento. } \\
\text { Se trabalha com estoques. } \\
\text { Efetividade da distribuição de } \\
\text { insumos e produtos. }\end{array}$ \\
\hline $\begin{array}{l}\text { Gestão das } \\
\text { Operações }\end{array}$ & $\begin{array}{l}\text { Ociosidade } \\
\text { Pontos críticos do processo } \\
\text { produtivo; } \\
\text { Controle de qualidade e normas de } \\
\text { certificação; } \\
\text { Desperdícios e perdas por }\end{array}$ & $\begin{array}{l}\text { Capacidade produtiva e produção } \\
\text { média mensal. }\end{array}$ \\
\hline
\end{tabular}




\begin{tabular}{|c|c|c|}
\hline & retrabalho. & \\
\hline Logística externa* & $\begin{array}{l}\text { Distribuição por região e estados; } \\
\text { Se a empresa é exportadora. }\end{array}$ & \\
\hline \multirow{9}{*}{$\begin{array}{l}\text { Marketing e } \\
\text { Vendas }\end{array}$} & $\begin{array}{l}\text { Existência de estratégias definidas } \\
\text { de marketing. }\end{array}$ & \\
\hline & Orientação para o mercado & Análise da satisfação dos clientes. \\
\hline & Produto & $\begin{array}{l}\text { Receptividade dos clientes com } \\
\text { relação ao produto. }\end{array}$ \\
\hline & Promoção & Uso de canal formal de divulgação \\
\hline & Preço & $\begin{array}{l}\text { Nível dos preços em relação à } \\
\text { concorrência. }\end{array}$ \\
\hline & Segmentação & $\begin{array}{l}\text { Escolha de canais segmentados } \\
\text { para divulgação. }\end{array}$ \\
\hline & Posicionamento do produto & \\
\hline & Fidelização de clientes & \\
\hline & Análise da concorrência & \\
\hline $\begin{array}{l}\text { Assistência } \\
\text { Técnica** }\end{array}$ & $\begin{array}{l}\text { Pedidos de assistência e tratamento } \\
\text { dispensado aos mesmos; } \\
\text { Garantias para o produto. }\end{array}$ & \\
\hline
\end{tabular}

Quadro 2 - Atividades da Cadeia de Valor abordadas na pesquisa Fonte: Albino et al. (2010).

* $e^{* *}$ representam fatores que não consideram outros elementos ou não apresentam desdobramentos.

O Quadro 3, a seguir, apresenta dados gerais sobre as empresas nas quais foram realizadas as entrevistas. 


\begin{tabular}{|c|c|c|c|c|}
\hline Empresa & $\begin{array}{c}\text { Número de } \\
\text { funcionários }\end{array}$ & $\begin{array}{l}\text { Tipos de produtos } \\
\text { produzidos }\end{array}$ & $\begin{array}{c}\text { Principal mercado } \\
\text { atendido }\end{array}$ & Instalações \\
\hline$A$ & 20 & $\begin{array}{l}\text { Meses tubulares de } \\
\text { linha popular } \\
\text { (móveis de aço). }\end{array}$ & $\begin{array}{c}\text { Região Sudeste, } \\
\text { principalmente Minas } \\
\text { Gerais }\end{array}$ & Alugadas \\
\hline B & 16 & $\begin{array}{l}\text { Infantis (linha } \\
\text { popular), espelhos } \\
\text { giratórios e } \\
\text { cômodas. }\end{array}$ & $\begin{array}{c}\text { Região Sudeste, } \\
\text { principalmente Minas } \\
\text { Gerais }\end{array}$ & Próprias \\
\hline $\mathrm{C}$ & 44 & $\begin{array}{l}\text { Estofados de Linha } \\
\text { popular. }\end{array}$ & Região Sudeste & Alugadas \\
\hline $\mathrm{D}$ & 31 & $\begin{array}{c}\text { Salas de jantar } \\
\text { (linha média-baixa). }\end{array}$ & Região Sudeste & Alugadas \\
\hline$E$ & 45 & $\begin{array}{l}\text { Estofados (linha } \\
\text { média) }\end{array}$ & $\begin{array}{l}\text { Nacional i) ampla } \\
\text { cobertura da região } \\
\text { Sudeste; ii) Bahia }\end{array}$ & Próprias \\
\hline$F$ & $\begin{array}{l}133 \text { diretos } \\
\text { e cerca de } \\
100 \\
\text { indiretos. }\end{array}$ & $\begin{array}{l}\text { Decorativos, racks e } \\
\text { estantes (linha } \\
\text { média e média-alta). }\end{array}$ & $\begin{array}{l}\text { Nacional i) ampla } \\
\text { cobertura da região } \\
\text { Sudeste ii) menor } \\
\text { cobertura dos } \\
\text { demais estados }\end{array}$ & Alugadas \\
\hline G & 135 & $\begin{array}{l}\text { Dormitórios e linha } \\
\text { infantil (média). }\end{array}$ & Nacional (ampla) & Alugadas \\
\hline $\mathrm{H}$ & 190 & $\begin{array}{c}\text { Decorativos, } \\
\text { dormitórios e salas } \\
\text { de jantar (média e } \\
\text { alta) }\end{array}$ & Nacional (ampla) & Próprias \\
\hline $\mathrm{I}$ & 250 & Estofado (linha alta) & Nacional (ampla) & Próprias \\
\hline $\mathrm{J}$ & 120 & $\begin{array}{l}\text { Decorativo e salas } \\
\text { de jantar (linha } \\
\text { média-alta e alta) }\end{array}$ & $\begin{array}{l}\text { Nacional (ampla) e } \\
\text { internacional } \\
\text { (América do Sul) }\end{array}$ & Alugadas \\
\hline $\mathrm{K}$ & 250 & $\begin{array}{c}\text { Decorativos, } \\
\text { dormitórios, camas, } \\
\text { modulares para } \\
\text { quarto e cozinha } \\
\text { (linha média-alta) }\end{array}$ & $\begin{array}{c}\text { Nacional (ampla) e } \\
\text { internacional } \\
\text { (América do Sul, } \\
\text { América Central) }\end{array}$ & Próprias \\
\hline$L$ & 500 & $\begin{array}{l}\text { Salas de jantar, } \\
\text { home theater, } \\
\text { cristaleiras e peças } \\
\text { decorativas (linha } \\
\text { alta) }\end{array}$ & $\begin{array}{c}\text { Nacional (ampla) e } \\
\text { internacional } \\
\text { (América do Sul, } \\
\text { América Central, } \\
\text { África, China) }\end{array}$ & Próprias \\
\hline M & 350 & $\begin{array}{c}\text { Dormitórios (classes } \\
B, C \text { e } D-\text { vai } \\
\text { inaugurar uma linha } \\
\text { alta) }\end{array}$ & $\begin{array}{l}\text { Nacional (ampla) e } \\
\text { internacional } \\
\text { (América do Sul, } \\
\text { América Central, } \\
\text { África, China e } \\
\text { algumas regiões da } \\
\text { Europa) } \\
\end{array}$ & Próprias \\
\hline $\mathrm{N}$ & 100 & $\begin{array}{l}\text { Racks, estantes e } \\
\text { cômodas (linha } \\
\text { média-alta e alta) }\end{array}$ & Nacional (ampla) & Próprias \\
\hline $\mathrm{O}$ & 180 & $\begin{array}{c}\text { Mesas, cadeiras e } \\
\text { sofás tubulares }\end{array}$ & Nacional (ampla) & Próprias \\
\hline
\end{tabular}

Revista Produção Online, v.11, n.1, p. 263-287, mar., 2011 


\begin{tabular}{|c|c|c|c|c|}
\hline & & (linha média-alta) & & \\
\hline $\mathrm{P}$ & 1400 & Armários de aço e & Nacional (ampla) e & Próprias \\
& & de madeira & (principalmente \\
& & $\begin{array}{c}\text { África do Sul, Angola } \\
\text { e países da América } \\
\text { do Sul). }\end{array}$ & \\
\hline
\end{tabular}

Quadro 3 - Dados gerais das empresas visitadas

Fonte: Elaborado pelos autores.

\section{RESULTADOS E DISCUSSÕES}

Esta seção busca investigar os padrões relacionados aos fatores condicionantes da dinâmica competitiva no APL moveleiro de Ubá, bem como estratificar os grupos de empresas estando dividida em duas partes: a) atividades de apoio contempladas no modelo da Cadeia de Valor e; b) atividades primárias contempladas no modelo da Cadeia de Valor.

\subsection{Cadeia de Valor - Atividades de apoio}

a) Infraestrutura - dimensões estudadas: Finanças, Planejamento Estratégico e Responsabilidade Social Empresarial (RSE).

No primeiro e segundo grupos, verifica-se um controle preciso e rigoroso das finanças como fluxo de caixa e identificação das necessidades de capital de giro. No terceiro grupo, existe também o cuidado com as finanças, porém, não no mesmo nível dos demais grupos. Atividades relacionadas ao planejamento estratégico são bastante assimiladas pelos grupos 1 e 2, que apresentam metas claras e exequíveis, bem como uma visão de futuro claramente delineada, elementos que, de acordo com Oliveira (2007), são essenciais ao planejamento. Já no terceiro grupo não foram identificados objetivos, visão e metas claras e explícitas, bem como outros elementos que integram atividades do planejamento estratégico. No caso do primeiro grupo, a RSE é assimilada, de modo que as empresas apoiam ou, em alguns casos, elaboram e desenvolvem por conta própria projetos para melhorias da localidade onde atuam. Observou-se no grupo com padrões intermediários variações quanto à dimensão $R S E$, sendo que algumas empresas se equiparam ao primeiro grupo e outras ficam mais próximas do terceiro grupo. No terceiro grupo, o 
desenvolvimento da RSE ainda é incipiente, sendo que alguns decisores, quando questionados, apresentaram perspectivas no sentido de agir de forma socialmente responsável, porém, alegaram que se faz pouco, pois fatores relacionados às questões de saúde financeira da empresa são prioritários e até impeditivos.

b) Gerenciamento de Recursos Humanos - dimensões estudadas: contratação e qualificação da mão de obra e benefícios oferecidos pelas empresas.

No primeiro grupo, a contratação dos colaboradores ocorre de forma bastante profissionalizada, procurando empregar métodos mistos para selecionar os candidatos. Araújo (2006) confere a esse método maior credibilidade e garantia de resultados positivos. Nessas empresas, existe o apoio de um profissional da área de psicologia que acompanha os testes, e é elaborado um processo seletivo composto por várias etapas. No segundo grupo, a contratação dos colaboradores também ocorre de forma profissionalizada, na maioria dos casos. A maioria das empresas do grupo não tem o profissional da área de psicologia em tempo integral na empresa, porém, são cuidadosas no decorrer do processo de recrutamento e seleção. No terceiro grupo, a contratação dos colaboradores é realizada muitas vezes informalmente, apenas por indicações de funcionários, sem um processo definido de seleção de pessoas.

Para as empresas do primeiro grupo, a qualificação da mão de obra empregada é boa, o que pode justificar o pagamento de salários um pouco acima da média dos concorrentes. No segundo grupo, pode-se notar que não existe grande satisfação por parte dos empregadores, de modo que alguns decisores até comentam que não substituem alguns funcionários por falta de mão de obra no mercado de Ubá e região. No terceiro grupo, observou-se baixa satisfação dos empregadores com a mão de obra, que, por sua vez, pode estar relacionada com o incipiente critério de contratação adotado por essas empresas. Em aspectos gerais, o gerenciamento dos recursos humanos do primeiro grupo é realizado de forma que parece satisfatória, procurando, em muitos casos, valorizar o colaborador, o que é previsto por Araújo, (2006). No segundo grupo, percebeu-se que a quantidade de 
benefícios oferecidos aos colaboradores é inferior à quantidade de benefícios oferecidos pelas empresas do primeiro grupo. Já o terceiro grupo, no que se refere aos benefícios oferecidos aos colaboradores, está aquém dos demais, e, em alguns casos, fica próximo do descumprimento de requisitos previstos por lei, como o caso de vale-transporte (Lei $N^{\circ} 7.418$, de 16 de dezembro de 1985).

c) Desenvolvimento de tecnologia - dimensões estudadas: parcerias para desenvolver novos produtos e processos e pesquisa de produtos ou de processos por conta própria.

No primeiro grupo, percebeu-se maior evolução que os demais no que se refere ao desenvolvimento de parcerias (principalmente com fornecedores) para criação de novos produtos e processos. Segundo os empresários desse grupo, estas parcerias são bastante exploradas, uma vez que os fornecedores viajam e conhecem novidades que podem atender melhor aos clientes, abastecem as empresas de informações e se tornam parceiros. Não ocorre, por exemplo, troca de fornecedor devido a uma pequena diferença nos preços praticados. Ocorrem, ao contrário, conversas e ajustes, no sentido de praticarem a cooperação, que é um dos pilares da cultura dos APLs (LASTRES; CASSIOLATO; MACIEL, 2003; GALDÁMEZ, et al., 2009).

As empresas do segundo grupo estão começando a trabalhar questões referentes às parcerias para desenvolvimento de novos produtos e processos, o que demonstra uma fase transitória e adaptativa, com alusão à teoria evolucionária nessa dimensão (WINTER, 2005; SOUZA, 2003; ALBINO, 2009). Já o terceiro grupo parece evitar envolvimento com as demais empresas do setor por julgarem suas empresas pequenas ou pouco desenvolvidas para estar no mesmo ambiente que as demais.

O primeiro grupo desenvolve novos produtos por conta própria e também inova no processo produtivo, de modo a produzir mais com custos menores, o que é previsto por Gouvêa e Plantulho (2008). No segundo grupo, o desenvolvimento de novos produtos ocorre de maneira mais individualizada, não ocorrendo muita cooperação, o que remete, muitas vezes, à visão do proprietário. No terceiro grupo, 
o este desenvolvimento é incipiente, sendo que a obtenção de novos modelos se dá sem o auxílio de parceiros. Ocorrem bastantes imitações, de modo que a partir do conhecimento das novidades o grupo possa desenvolver seus próprios.

d) Aquisição - dimensões estudadas: Qualificação das pessoas do setor de compras e estreitamento das relações com fornecedores.

Nas empresas com padrões mais avançados existem colaboradores específicos para a função de compras, ocorrendo intervenções dos sócios somente em alguns casos. O segundo grupo apresenta notas um pouco inferiores às do primeiro e terceiro grupos, o que não era esperado. As possíveis explicações são as seguintes: o primeiro grupo conta com mão de obra suficientemente qualificada para efetuar as atividades de aquisição e o terceiro grupo, na maioria dos casos, concentra essa atividade como uma das atribuições dos sócios. Já o grupo dois fica em situação intermediária pelo fato de não ter ainda recursos humanos com plena capacitação para o exercício dessa tarefa e também não conta com a presença do proprietário em todas as atividades, devido ao fato de este delegar funções para ter tempo de pensar no negócio de forma global e estratégica. No terceiro grupo merece destaque a presença do sócio proprietário (considerado como pessoa qualificada para a função compras) não apenas para fins de fiscalização do processo, mas pelo envolvimento direto com as negociações, de modo que o grupo obteve notas semelhantes às do segundo grupo, embora se esperasse que o segundo grupo, estando relativamente mais avançado que o terceiro, obtivesse menores notas.

No primeiro grupo, observou-se que as empresas procuram se aproximar de seus fornecedores de maneira contínua, visando a obter parcerias com eles, o que reforça a questão referente ao desenvolvimento de tecnologia (GOUVÊA; PLANTULHO, 2008). O segundo grupo se mostra também em situação intermediária, estando mais próximo do primeiro grupo do que do terceiro. (SOUZA, 2003). Os resultados das empresas do terceiro grupo foram mais baixos que os dos demais grupos. Há concentração de atividades por parte do empreendedor, que se torna responsável pelas compras e pelo contato com o fornecedor. 


\subsection{Cadeia de Valor - Atividades primárias}

a) Logística interna - dimensões estudadas: existência de um setor efetivo de recebimento de mercadorias, existência de um sistema organizado de distribuição interna e estocagem.

No primeiro grupo, pode-se verificar a existência de um setor efetivo para recebimento de mercadorias, com pessoas qualificadas e responsáveis pela verificação de toda a matéria-prima que entra nas fábricas (DIAS, 2006). Observamse, no segundo grupo, falhas no recebimento de mercadorias. Em algumas unidades, já se pode observar que a função de recebimento de mercadorias é delegada a um único responsável (ou equipe responsável), mas que esta equipe, em alguns casos, tem muitas outras atribuições além da atividade de recebimento. No terceiro grupo, o recebimento das matérias-primas não ocorre de maneira organizada, de modo que a pessoa que estiver disponível no momento da chegada de materiais é quem os recebe.

Não há um treinamento específico para o recebimento de cargas, o que pode dificultar a sistematização do processo. O primeiro grupo se manteve com padrões considerados superiores nas questões de logística interna, com pouco retrabalho de distribuição interna. No segundo grupo, observa-se a existência de falhas na distribuição interna, que, contudo, não ocorrem com muita frequência. No terceiro grupo, a distribuição interna não segue procedimentos sistemáticos, e, como alguns próprios empresários frisaram, é comum um colaborador ter que atravessar todo o galpão da produção para buscar uma lixa ou algo simples que tenha faltado no momento da produção, o que gera atrasos.

Com relação à estocagem, no primeiro grupo, ocorre o uso do estoque regulador, descrito por Dias (2006) como aquele que visa a atender às demandas pouco antes do esgotamento total do estoque. Quando se utiliza o estoque regulador, outro pedido de material já deve ter sido efetuado, de forma que a empresa não ficará sem produzir. Nessas empresas, no caso de algumas matériasprimas específicas, tem-se um estoque mais alto, devido ao fato de o acesso a elas ser dificultado pela distância entre fornecedores e empresas, caso das madeiras e aglomerados. No segundo grupo, há também o uso de estoques reguladores, mas 
percebe-se pelas notas obtidas que o nível de estoque de produtos acabados aumenta um pouco se comparado ao primeiro grupo. O terceiro grupo, em sua grande maioria, acredita que possuir o estoque de produtos acabados gera resposta rápida às demandas dos clientes, desconsiderando o aspecto do custo de armazenagem.

b) Gestão das operações - dimensões estudadas: produção média mensal, como uma medida de desempenho, objetivando saber se a capacidade produtiva é bem explorada, utilização de mecanismos de controle de qualidade e de normas de certificação, e desperdícios e perdas por retrabalho. Foi observada também a existência de pontos críticos no processo produtivo.

Em todas as unidades do primeiro grupo, a produção média fica acima de $85 \%$ da capacidade total de produção. No segundo grupo, a produção média é menor, tendo como principal justificativa para a baixa produção, a crise financeira que afetou o mercado para o tipo de móvel disponibilizado por boa parte desse grupo. A média de produção varia entre as unidades, sendo que uma delas apresenta produção média entre $51 \%$ e $60 \%$, e as demais variam entre $61 \%$ e $80 \%$ da capacidade produtiva. No terceiro grupo, pode-se observar que apenas uma empresa tem mantido o percentual de $80 \%$ de sua capacidade, duas unidades mantêm a produção em torno de $70 \%$ e outras duas estão abaixo de $60 \%$ da capacidade produtiva, fatos que foram justificados também pelos impactos da crise financeira.

A utilização de mecanismos de controle de qualidade e de normas de certificação pelas empresas do primeiro grupo são indícios de uma produção bem planejada e de acordo com pré-requisitos que atendam às demandas referentes à preservação ambiental. No segundo grupo, quanto aos mecanismos de controle de qualidade, principalmente aqueles relacionados com a preservação ambiental, também se pode perceber que o grupo está se reestruturando e que existem muitos aspectos a serem trabalhados. São utilizados poucos mecanismos de controle de qualidade pelo terceiro grupo, o que pode ser responsável por produtos com baixa uniformidade. No primeiro grupo, verifica-se um controle rigoroso das operações, de modo a evitar que ocorram desperdícios. As dimensões referentes à gestão das 
operações do segundo grupo apresentam sinais de evolução de padrões. Pode-se perceber que as perdas são mais frequentes nesse grupo do que no primeiro. Essa dimensão, segundo os entrevistados, também tem sido trabalhada e melhorada de forma contínua. No terceiro grupo, os desperdícios e perdas por retrabalho são frequentes e uma possível explicação para tal fato reside na falta de procedimentos sistematizados para as operações. Invariavelmente todos os grupos apresentaram queixas com relação à falta de mão de obra qualificada, até mesmo o primeiro grupo, que conta com pessoas mais bem qualificadas.

c) Logística externa - dimensões estudadas: facilidades de acesso à empresa por meio da existência de representantes distribuídos por regiões, de modo a relacionar o percentual de vendas de determinada região com a existência de representantes; se as empresas são exportadoras ou não, e, para o caso de ser exportadora, procurou-se identificar o quanto representa o mercado externo para as empresas visitadas.

As empresas do primeiro grupo apresentam seus representantes bem distribuídos, existindo alguma carência com relação à Região Norte do país. Nessa região, existem poucos representantes, porém, existe o cuidado por parte de todas as empresas do grupo, no sentido de manter o sistema de vendas pela Internet bastante ativo. No segundo grupo, também há representantes distribuídos em várias regiões do país, o que se pode considerar como uma cobertura geográfica ampla.

As empresas do terceiro grupo atendem mais o mercado local (dentro do próprio Estado de Minas Gerais e regiões periféricas do Rio de Janeiro e Espírito Santo) e têm poucos representantes. Todas as empresas do primeiro grupo são exportadoras, porém, com exceção de uma empresa que tem grande parcela da produção destinada ao mercado externo, as demais apresentam pequena atuação no nesse mesmo mercado. No segundo grupo, apenas uma empresa é exportadora, porém, outras três apresentam planos de exportar nos próximos dois anos, e já estão em fase de tramitação dos procedimentos burocráticos necessários para iniciar as atividades de exportação. No terceiro grupo, nenhuma das empresas é exportadora, e apenas uma tem planos de começar a exportar. Tal fato pode ser 
justificado pelo tipo e qualidade dos produtos, uma vez que não se tem um bom controle da produção e o mercado externo não irá absorver essa produção.

d) Marketing e vendas - dimensões estudadas: existência de estratégias de marketing, orientação para o mercado (satisfação dos clientes), preço e segmentação.

Verificou-se, para o primeiro grupo, a existência de estratégias de marketing que visam a divulgação do produto, fortalecimento da marca, fidelizar clientes, estudar a concorrência, entre outros aspectos passíveis de serem identificados a partir do uso de determinada estratégia. No segundo grupo, as estratégias de marketing visam sempre à divulgação do produto e análise da concorrência, ocorrendo, em alguns casos, o interesse por reforçar a marca. No terceiro grupo, com as questões relacionadas com estratégias de marketing, percebeu-se que há interesse em simplesmente divulgar o produto, ocorrendo desconhecimento de outros aspectos que podem ser abordados ao se estabelecer uma estratégia.

Dos cinco entrevistados desse grupo, três afirmam não ter uma estratégia de marketing estabelecida. Pode-se perceber que a satisfação dos clientes é fundamental para o primeiro grupo, de modo que a tomada de decisões se dá, na maioria das vezes, a partir do que os clientes falam. No segundo grupo, a orientação para o mercado (satisfação do cliente) é bastante almejada, sendo que em muitos casos, assim como no primeiro grupo, decisões são tomadas com base nas ideias dos clientes. No terceiro grupo, as empresas começam a identificar no cliente um potencial informante, mas tal fato ainda é incipiente, refletindo a falta de orientação para o mercado (KERIN, et al., 2007). No primeiro grupo, as empresas utilizam estratégias de alto preço ou preço prêmio, que consiste no oferecimento de produtos a preços elevados, porém, com características que justificam esses preços (KERIN, et al. 2007). O preço dos produtos das empresas do segundo grupo é considerado equivalente aos dos concorrentes diretos enquanto o preço dos produtos das empresas do terceiro grupo é considerado na média dos concorrentes, e, em alguns casos, abaixo da média.

No primeiro grupo, a divulgação se dá por anúncios em revistas especializadas do setor, participação em eventos, como rodadas de negócios, feiras, 
desde que sempre voltadas para o público-alvo das empresas, entre outras formas de se promoverem. No segundo grupo, ocorrem algumas falhas no que se refere à seleção dos meios de divulgação. Já no terceiro grupo, como uma decorrência da falta de divulgação, pode-se afirmar que não são adotados critérios de segmentação, pois muitas empresas ainda não chegaram ao estágio anterior ao da segmentação, que é o de pretender divulgar a marca. Para aqueles que divulgam, haveria espaço para iniciativas que promovam critérios de segmentação.

e) Assistência técnica - dimensões estudadas: quantidade de solicitações de assistência por período e forma como a empresa atende a essas solicitações.

No primeiro grupo, os entrevistados explicaram que a quantidade de pedidos de assistência é pequena, pois, na maioria dos casos, o móvel é entregue na casa do cliente mediante assinatura do responsável pelo recebimento, comprovando que o mesmo está em conformidade com o pedido. Esse procedimento tem evitado reclamações posteriores. No segundo grupo, ocorre um número maior de solicitações de assistência. A quantidade de solicitações de assistência técnica que ocorre no terceiro grupo é cerca de $70 \%$ mais elevada que no primeiro grupo e $25 \%$ mais elevada que no segundo grupo. Tal fato poderia ser justificado pela baixa qualidade dos produtos percebida nesse grupo.

Para o primeiro grupo, quando ocorrem reclamações, os entrevistados foram categóricos ao afirmar que a solicitação de assistência tem prioridade total na empresa, e estão cientes de que é mais difícil recuperar um cliente perdido do que conseguir um novo cliente. A partir dos fatores estudados com base na cadeia de valor e dos padrões identificados pelos grupos de empresas, destacam-se alguns aspectos em que os grupos se diferenciam mais, como o produto produzido, o processo produtivo adotado, o mercado atendido e a gestão das empresas.

\section{CONCLUSÕES}

Trabalhos anteriores estudaram o polo moveleiro de Ubá a partir do modelo do Diamante de Porter, estratificaram o APL em padrões produtivos a partir da percepção de especialistas e desenvolveram a estrutura analítica a ser aplicada. 
Este estudo de caso apresentou uma aplicação da estrutura analítica da Cadeia de Valor, e representa uma continuação dos estudos dos autores na área da competitividade em aglomerações produtivas.

Ressalta-se que tal estudo procurou detalhar aspectos da produção moveleira ubaense a partir dos elementos previstos no modelo da Cadeia de Valor expostos no Quadro 1. Assim, acredita-se que este artigo apresenta riqueza de informações acerca das diversas áreas que podem ser estudadas no setor produtivo moveleiro.

Pode-se confirmar, a partir das visitas às empresas moveleiras de Ubá, a premissa da estratificação em grupos com diferentes padrões competitivos. O grupo com empresas de padrões avançados, se destacou em muitas atividades previstas na cadeia de valor, principalmente no que se refere aos investimentos em marketing e vendas e a maioria das empresas desse grupo exporta para diversos países.

O grupo com empresas de padrões intermediários parece não apresentar um padrão bem definido de desempenho nas atividades da cadeia de valor, estando em fase de mudanças, principalmente no que se refere à gestão. Assim, foi possível encontrar empresas cujos padrões se aproximam do primeiro grupo, e também padrões mais próximos aos das empresas do terceiro grupo. Identificou-se nesse grupo empresas exportadoras e não exportadoras.

O grupo com empresas de padrões retardatários se apresenta incipiente nas atividades da Cadeia de Valor e se verificou que nenhuma das empresas estudadas vende para o mercado exterior, nem tem planos para isso. Tal fato se deve, principalmente, à elas ainda necessitarem resolver questões administrativas, bem como problemas relacionados ao processo produtivo, o que reflete diretamente na baixa qualidade e não uniformidade dos produtos.

Pode-se afirmar que, no campo científico, esta pesquisa apresenta contribuição por explorar a abordagem estratificada no setor de móveis que antes não havia sido estudado in loco à luz de tal abordagem.

Como propostas futuras, sugere-se a investigação de outros APLs com a utilização da abordagem estratificada, pois ela apresenta potencial para investigação da diversidade interna em aglomerações industriais. Outra sugestão para futuras pesquisas emerge da própria teoria na qual esse trabalho foi embasado, que prevê, além da estratificação em grupos, a formação de uma trajetória competitiva, de 
modo que estudos futuros podem verificar a posição das empresas estudadas e verificar se elas continuam ocupando as mesmas posições, bem como apresentar a trajetória por elas percorrida. Ainda, análises que levem mais em consideração o processo produtivo das empresas e se aprofundem nele, podem gerar resultados expressivos no sentido de identificar pontos que merecem destaque para melhorias.

Outra contribuição deste trabalho ocorre por terem sido apresentadas informações diferenciadas e que assumem caráter relevante para futuros direcionamentos das ações das empresas do APL moveleiro de Ubá. Tais informações estão dispostas de modo a apresentar as características de cada grupo, em que as empresas podem identificar suas práticas inseridas nos grupos, o que pode ajudar a gerar mudanças de padrões competitivos a partir do conhecimento dos pontos a serem desenvolvidos.

\section{REFERÊNCIAS}

ALBINO, A. A., SOUZA, S. D. C. Aplicação do Modelo Diamante de Porter e análise dos determinantes da competitividade para o APL Moveleiro de Ubá. In: SIMPÓSIO DE ENGENHARIA DE PRODUÇÃO, 2008, Bauru. Anais... Bauru: UNESP, 2008

ALBINO, A. A., LIMA, A. A. T. F. C., BEHR, R. R., SILVA, F. C. O APL Moveleiro de Ubá: formação de grupos e atuação direcionada do Poder Público. In: ENCONTRO NACIONAL DE PESQUISADORES EM GESTÃO SOCIAL, 3., 2009, Petrolina; Juazeiro. Gestão social e políticas públicas de desenvolvimento: ações, articulações e Agenda. Petrolina; Juazeiro. RGS, 2009.

ALBINO, A. A. Uma abordagem evolucionária do APL moveleiro de Ubá: competitividade e Políticas Públicas estratificadas. Dissertação (Mestrado) Universidade Federal de Viçosa, Viçosa: 2009.

ALBINO, A. A.; LIMA, A. A. T. F. C.; SOUZA, S. D. C.; BEHR, R. R. Competitividade e papel do Poder Público a partir da perspectiva Evolucionária. In: ENCONTRO NACIONAL DE PESQUISADORES EM GESTÃO SOCIAL, 4. Anais...Lavras, 2010.

ARAÚJO, L. C. G. de. Gestão de pessoas. São Paulo: Atlas, 2006.

BALESTRIN, A., VARGAS, L. M. A dimensão estratégica das redes horizontais de PMEs: teorizações e evidências. Revista de Administração Contemporânea. $p$. 203-227, 2004.

BRASIL. Lei sobre Vale-transporte - Disponível em: <http://www.planalto.gov.br/ccivil 03/LEIS/L7418.htm>. Acesso em: 19 set. 2009. 
BRUYNE, P. De, HERMAN, J. e SCHOUTHEETE, M. De. Dinâmica da pesquisa em ciências sociais - os polos da prática metodológica. Rio de Janeiro, 1991.

CARRIE, A. Integrated clusters - the future basis of competition. International Journal of Agile Management Systems Year, v. 1, p. $45-50$ p., 1999.

CRAIN D. W., ABRAHAM S. Using value-chain analysis to discover customers strategic needs. Strategy \& Leadership, v. 36, n. 4, p. 29-39, 2008.

DIAS, M. A. P. Administração de materiais: princípios, conceitos e gestão. 5. ed. São Paulo: Atlas, 2006.

DOSI G. Sources, procedures and microeconomics affects of innovation. Journal Economic Literature, v. 26, p.1120-1171, 1988.

FERRAZ, J. C., KUPFER, D., HAGUENAUER, L. Made in Brasil: desafios competitivos para a indústria. Rio de Janeiro: Campus, 1997.

GALDÁMEZ, E. V. C., CARPINETTI, L. C. R., GEROLAMO, M. C. Proposta de um sistema de avaliação de desempenho para Arranjos Produtivos Locais. Gestão da Produção, São Carlos, v. 16, n. 1, p. 133-151, jan./mar., 2009.

GOUVÊA, M. A., PLANTULHO, V. L. Indicadores de desenvolvimento tecnológico de empresas no setor industrial. Revista de Administração UFSM, v. 1, n. 2, p. 179192, mai./ago. 2008.

INTERSIND Informativo do Sindicato Intermunicipal das Indústrias do Mobiliário de Ubá. v.1, n.3, nov. 2008.

KERIN, R. A., HARTEY, S. W., BERKOWITZ, E. N., RUDELIUS, W. Marketing. 8. ed. São Paulo: Mc-Graw-Hill, 2007.

$\mathrm{KOH}, \mathrm{C}$. E., NAM K. "Ted". Business use of the internet: A longitudinal study from a value chain Perspective. Industrial Management \& Data Systems ,v. 105, n. 1, p. 82-95, 2005.

LASTRES, H. M. M., CASSIOLATO, J. E., MACIEL, M. L. (Orgs). Pequena empresa: cooperação e desenvolvimento local. Rio de Janeiro: Relume Dumará, 2003.

LICZBINSKI, C. R., KELM, M. L., ABREU, A. F. Informações fundamentais ao gerenciamento das atividades da Cadeia de Valor - o caso das pequenas empresas industriais de produtos alimentares. In: ENCONTRO NACIONAL DE ENGENHARIA DE PRODUÇÃO, [n.] 2002, Curitiba. Anais ... Curitiba: editor, 2002.

MOORI, R. G.; ZILBER, M. A. Um Estudo da cadeia de valores com a utilização da análise fatorial. Revista de Administração Contemporânea, v.7, n. 3, p.127-147, jul./set. 2003. 
NADER, B.; SACHS, P. F. T. Sistemas de gestão da produção e a cadeia de valor mineral. Disponível em:

<http://www.brasilminingsite.com.br/anexos/artigos/33_0.pdf>. Acesso em: 10 dez. 2009.

NELSON R.R , WINTER, S.G. An evolutionary theory of economic change. Cambridge, Mass: Belknep; Harvard University, 1982.

OLIVEIRA, D. P. R. de. Estratégia empresarial e vantagem competitiva: como estabelecer, implementar e avaliar. 5.ed. São Paulo: Atlas, 2007.

PORTER, M. E. A vantagem competitiva das nações. 7.ed. Rio de Janeiro: Campus, 1989.

PORTER, M. E. Vantagem competitiva. Rio de Janeiro. Campus, 1992.

PORTER, M. E., MILLAR, V. E. Como a informação proporciona vantagem competitiva. In: Competição on competition: estratégias competitivas essenciais. Rio de Janeiro: Campus, 1999.

SHANK, J.K. \& GOVINDARAJAN, V. Strategic cost management: the new tool for competitive advantage. New York: The Free, 1993.

SOUZA, S.D.C. Uma abordagem evolucionária da dinâmica competitiva em arranjos produtivos locais. 2003. 348p. Tese (Doutorado) - Universidade Estadual do Norte Fluminense, 2003.

SOUZA, S. D. C.; ARICA, J. Mudança tecnológica e estratificação competitiva em um arranjo produtivo do setor ceramista. Revista Produção, Brasil, v. 16, n. 1, p. 088-099, 2006.

WINTER, S. G. Developing evolutionary theory for economics and management: The Oxford Handbook of Management Theory. Oxford University Press. 2005.

ZENONE, L. C. Marketing estratégico e competitividade empresarial: formulando estratégias mercadológicas para organizações de alto desempenho. São Paulo: NOVATEC, 2007.

ZIJIM, W. H. M., BUITENHEK, R. Capacity planning and lead time management. International Journal of Production Economics. v. 46-57, p.165-179, 1996.

ZOKAEI, A. K.; SIMONS, D. W. Value chain analysis in consumer focus improvement: a case study of the UK red meat industry. The International Journal of Logistics Management, v. 17. p. $141-162,2006$.

\footnotetext{
${ }^{i}$ Modelo que procura identificar as condições de fatores, condições de demanda, existência de indústrias correlatas e de apoio, estratégia, estrutura e rivalidade entre empresas, considerando também aspectos como o acaso e papel do governo.
} 
ii Baseado na interdependência, articulação e vínculos consistentes para gerar interação, cooperação e aprendizagem.

iii Para trabalhos que utilizaram o modelo da Cadeia de Valor, porém para outras aplicações ver: Linzbinski, Kelm e Abreu (2002); Moori e Zilber (2003); Koh e Nam (2005); Zokaei e Simons (2006); Nader e Sachs (2008); Crain e Abraham (2008).

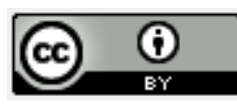

Artigo recebido em 04/11/2010 e aceito para publicação em 27/01/2011. 